\title{
ICT enabled cross-sector collaboration in emergency response: emerging forms of public-sector network governance
}

\section{S. Pilemalm*}

Department of Management of Engineering,

Linköping University,

Linköping, 581 83, Sweden

Email: sofie.pilemalm@liu.se

${ }^{*}$ Corresponding author

\section{K. Yousefi Mojir}

Faculty of Librarianship, Information, Education and IT, University of Borås, 501, 90, Borås, Sweden

Email: kayvan.yousefi_mojir@hb.se

\begin{abstract}
Information and communication technology (ICT) has enabled the pooling of emergency response resources. Here, we explore and compare three cases of cross-sector collaboration: co-location, co-use of resources and semi-professionals as first responders. Identified opportunities include shared facilities and equipment, and a positive attitude towards the new collaboration. Challenges include undefined roles, responsibilities, difficulties in prioritising among ordinary and new tasks in resource-strained organisations; and lack of legislation, and agreements. Reported needs related to improved training and joint exercises, to trauma support and basic supplies, e.g., blankets, reflective vests, and warning triangles. ICT suggestions included, e.g., systems for errand handling, joint assessment of information, status and acknowledgement of available and dispatched resources, and smartphone-based dispatch management. The emerging collaborations can be seen as hybrid forms of government and network governance. Network governance may thus support the development of their institutional aspects, but needs to be complemented with practical elements relating to the emergency response context.
\end{abstract}

Keywords: emergency response; ICT; information and communication technology; cross-sector collaboration; network governance; public sector; co-use; co-location; semi-professionals.

Reference to this paper should be made as follows: Pilemalm, S. and Yousefi Mojir, K. (2020) 'ICT enabled cross-sector collaboration in emergency response: emerging forms of public-sector network governance', Int. J. Emergency Management, Vol. 16, No. 3, pp.249-280.

Biographical notes: S. Pilemalm is Professor in Informatics and the Director of Centre for Advanced Research of Emergency Response (CARER), residing at Linköping University, Sweden. She received her PhD in 2002 and has since worked as Researcher and Consultant for the Swedish Defence Research Agency before returning to the university in 2011. Here she has established an inter-disciplinary research environment on terms of new actors, 
new collaboration forms, new structures and new methods and ICT support in emergency management and the incident site of the future. She has many years of experience in user-centred systems development and has led several systems development projects and design groups in such areas as non-profit organisations, the Swedish Defence, crisis management and response systems. She is an active researcher in the security arena both at national and international level and has a great number of publications and review assignments in related scientific journals and conferences.

K. Yousefi Mojir is a Researcher and Lecturer in Informatics and Information Architecture at Borås University in Sweden. He received his $\mathrm{PhD}$ in 2018 from Linköping University in Sweden, in the field of Information Systems Development with a specific focus on emergency management context and cross-sector collaborations. His research focuses on user-centred information systems development and the related socio-technical and institutional factors. He has participated in different projects to strengthen emergency response, i.e., to create cross-sector collaborations and to develop related information systems. He has also published several articles in related scientific journals and conferences. He is also active in the field of information architecture (IA) concerning how to organise, present and share information between organisations mainly in relation to the future crisis management.

\section{Introduction}

In recent decades, the public sector across the world has had to deal with increasing challenges, natural disasters, increased socio-economic gaps, urbanisation with depopulation of rural areas, aging populations, migration streams, war and terrorism (e.g., Haddow et al., 2013) This has taken place against a background in which the sector has often experienced substantial financial cutbacks and resource shortages. Emergency response organisations in specific, at the same time as having to deal with the increasing frequency of extraordinary events, crises and catastrophes, also have to continue to respond to everyday frequent emergencies, such as traffic accidents, fires, drownings, heart failures, and criminal actions, often in a financially strained environment and/or in a context of scarce personnel resources. This puts a tremendous strain on contemporary response organisations.

One way to cope with these societal developments is to create cross-sector collaborations combining resources from various sectors, including private organisations, various public organisations, non-governmental organisations and citizens. Cross-sector collaboration which has been applied in various areas, such as addressing climate change, environmental protection, tackling poverty, natural resource management, bridging the educational achievement gap, and crisis and emergency management (Agranoff, 2007; Agranoff and McGuire, 2010; O'Leary and Bingham, 2009; Bryson, 2004; Vigoda, 2003). As for emergency response, using security officers in the USA to assist in life-threatening emergencies is one example (Valenzuela et al., 2000). Patton (2007) listed several possible groups that are helpful in completing and strengthening local capacity to deal with emergencies; for example, subject-matter experts, community-based organisations, social service agencies, civic groups, private businesses, and media organisations. In Sweden, groups such as guard companies, nurses, taxi drivers and civil 
voluntee654werrs have been engaged in various collaborations with the municipal rescue services, the national alarm centre and the police (e.g., Ramsell et al., 2017).

Cross-sector collaborations have been studied from various perspectives and employing different theories, including network governance co-production, policy networks, and new public management (e.g., Pestoff et al., 2013; Agranoff, 2007; Carlsson, 2000). 'Network governance' and 'cross-sector collaboration' are terms that are actually sometimes used interchangeably in the research literature (e.g., Agranoff, 2007; Jones et al., 1997). From a theoretical perspective, it is thus possible to see these emergency response collaborations as an emerging form of network governance, i.e., autonomous partners engaged in addressing a common issue or problem insufficient professional first-response resources - and joint delivery of public services through horizontal networking and the sharing of resources (Klijn and Koppenjan, 2012; Jones et al., 1997). At a general level emerging governance forms are enabled by governments' access to modern information and communication technology (ICT) (Yousefi Mojir et al., 2016). It has meanwhile been argued that perspectives taken from the information systems (IS) research field are increasingly needed to complement the above perspectives, which largely stem from policy science (Melin and Wihlborg, 2018; Loukis et al., 2016; Janowski et al., 2012; Dawes, 2009).

In the domain of emergency response/cross-sector collaboration, most studies have focused on such aspects as medical issues (Weisfeldt et al., 2010), economics (Weinholt and Andersson Granberg, 2015), technological improvement (Jaeger et al., 2007) or on the general effect of the collaborations (Drezner et al., 2009), mainly in relation to large-scale emergencies and ad-hoc organisation. A few studies have also included accidents on a smaller scale and include collaboration opportunities, challenges and the need for support as well as on the related business and development processes (e.g., Ramsell et al., 2017; Yousefi Mojir and Pilemalm, 2014, 2016; Pilemalm et al., 2013). However, to enable the development of more systemised knowledge and general conclusions on cross-sector collaboration in emergency response, it seems crucial to compare and contrast various different collaborative initiatives, identifying similarities and differences, and relating them to factors such as steering mechanisms, policy analysis and juridical matters, and to basic needs for training, equipment and IT support. It is also interesting to connect the application domain to theory and a broader public-sector perspective where IT is used to enable and sustain cross-sector networks in pursuit of public-sector goals.

\subsection{Study aim and objectives}

In this study, we focus and cross-compare three cases of cross-sector collaboration and the pooling of resources from different professions in day-to-day Swedish emergency response in order to:

- identify similarities and differences regarding opportunities, challenges, and needs for support in terms of organisation, legal matters, training and ICT artefacts

- $\quad$ perform an analysis under the theoretical lens of network governance to place the collaborations in a wider public-sector context and assess the theory's usefulness when developing and implementing future emergency response cross-sector collaborations. 
The study thus takes place within the Swedish emergency response system (ERS), but could also be of interest to similar emerging cross-sector collaborations and public-sector network contexts. Specifically, it may apply to emergency response in other countries since many basic tasks and goals of first response are similar and, thus, they have the same basic related needs. From a theoretical point of view, the results may be useful to researchers generally interested in the interplay between ICT, public sector innovation, governance, and networks, with a specific focus on network governance in emerging emergency response cross-sector collaborations.

\section{Background}

In this section, we first describe the emerging trends in public sector cross-sector collaboration with specific focus on the emergency response study context and then network governance.

\subsection{Emerging trends in public-sector cross-sector collaboration}

In the context of this study, we define cross-sector collaboration as a process in which different autonomous actors from different societal sectors (e.g., the public sector, private sector, non-profit sector) or even within the public sector (e.g., healthcare, emergency response, social care) attempt to create a new setting by establishing new ways of sharing information, resources and capabilities by performing joint response operations in order to achieve shared goals, i.e., saving lives and minimising environmental damage

Even though this has not been the focus of previous research, the perceived increase in collaboration in recent years seems to be closely related to modern and accessible ICT that supports communication, information sharing, decision-making and so on. Greater efficiency, reduced bias, higher quality of services, and improved organisational accountability are some examples of the perceived benefits of cross-sector collaboration (e.g., Alford and O'Flynn, 2012; Brinkerhoff, 2002). Meanwhile, a number of studies also argue that achieving collaboration is difficult (Bryson, 2004; Greve and Hodge, 2005; Huxham and Vangen, 2000). Identified challenges include distrust, managerial complexity, cultural conflict, power imbalances, risk of dependence, and lack of incentive for collaboration (Babiak and Thibault, 2009; Gazley and Brudney, 2007; Young, 2000).

In relation to emergency response, cross-sector collaboration has mainly focused on large-scale crisis management; for example, in citizen co-production and the role of non-profits in natural disasters (Chatfield and Reddick, 2018; Simon and Angela, 2007). Meanwhile, cross-sector collaborations have also begun to emerge in relation to frequent small accidents, not least in Sweden where public-sector challenges also include the continuing depopulation of rural areas, in particular in the country's northern parts, and a corresponding rapid growth of cities, to which recent immigration has contributed. At the same time, there has been a trend towards the centralisation of response resources in both rural and urban areas, where local fire units and police command centres have been merged into regional federations, have become fewer and spread over larger geographical areas. This has led to difficulties in providing continuous high-quality public service delivery, and in maintaining or reducing response times (e.g., Pilemalm, 2018; Yousefi Mojir and Pilemalm, 2016). To address these issues, new constellations 
and cross-sector collaboration forms are developed and successively implemented. Examples include municipal rescue services and elderly care nurses being dispatched together on some medical alarms, "while waiting for the ambulance" (Swedish abbreviation: IVPA). Another is when various occupations, e.g., nurses, taxi drivers, technicians/caretakers, guard companies and shop personnel receive basic training in first response, and are dispatched on certain alerts if they are close to an incident scene, to take basic action while waiting for the professional response resources (Yousefi Mojir et al., 2018). This study reports from three different examples of cross-sector collaboration in emergency response that have emerged in the past decade:

- Co-location of professional response actors and non-profit organisations in the Safety House in Östersund.

- Co-use of resources and collaboration between the rescue services, the social care unit and the technical division in Nyköping municipality.

- Collaboration of the municipal rescue services with home care personnel, fire services day personnel, guards and technicians in Norrköping municipality, in a study called semi-professionals.

\subsection{Cross-sector collaboration as network governance}

As mentioned, the emerging trends in cross-sector collaboration can be discussed and studied from various perspectives and employing various theories. We have chosen to focus on network governance. Network governance is primarily described as a phenomenon referring to horizontal collaboration between autonomous actors with shared interests, leading to collective service delivery or decision-making. Its core assumption is that the network consists of autonomous actors who interact to make policies and perform service delivery in a horizontal pattern without any clear top-down governing mechanism; being based instead on mutual interests or contracts (Jones et al., 1997). There have also been attempts to theorise around the term in order to explain under what conditions networks emerge, thrive and have advantages (e.g., Jones et al., 1997). Although, as mentioned previously the terms have sometimes been used interchangeably in the research literature (e.g., Agranoff, 2007) we here make a distinction between them and that we consider cross-sector collaboration as a phenomenon, process and an instantiation of network governance which is broader (including also, e.g., citizen engagement), and includes identified key factors, theoretical components and sub-categories, as described below.

Network governance is usually categorised into three major types (Antivachis and Angelis, 2015). Participant networks governance is based on meetings, shared interests, an equal basis for all participants and is markedly decentralised. Lead organisation governance occurs when an organisation undertakes the lead role in the coordination of members. Network administration organisation has a distinct and external governance entity that is not a member of the network. Network governance usually includes a number of key factors, which can either promote or hinder the network, sometimes depending on their prevalence or absence.

Thus far, network governance theory or perspectives have been applied mainly when studying public administration, inter-organisational relationships, new public management, public-private partnerships, stakeholder and citizen involvement, network 
societies, horizontal interactive decision-making, and public sector innovation, with no explicit connection to ICT (e.g., Pestoff et al., 2013; Agranoff and McGuire, 2010; O'Leary and Bingham, 2009; Carlsson, 2000). However, recently, Loukis et al. (2016) have pointed out that the relationship between network governance and technology is actually bi-directional and that "evolutions in IT enable the development of new types of network collaborations and governance, whereas governance of collaboration networks is critical for the development of complex IT infrastructures" (p.7). They argue that network governance should be conceptualised as socio-technical processes that are directly shaped by the involved actors when tackling complex and dynamic contemporary challenges. Janowski et al. (2012) described how organisations and sectors increasingly have to work through networks in order to organise existing resources and capabilities claiming that the new paradigm increasingly relies on IT to connect the actors and to build, manage and sustain relationships between them. Janssen and Estevez (2013) describe a new wave of 'I-government', transcending traditional public-sector organisational boundaries and relying on recent developments in technology.

Figure 1 A network governance framework for analysis of cross-sector collaboration

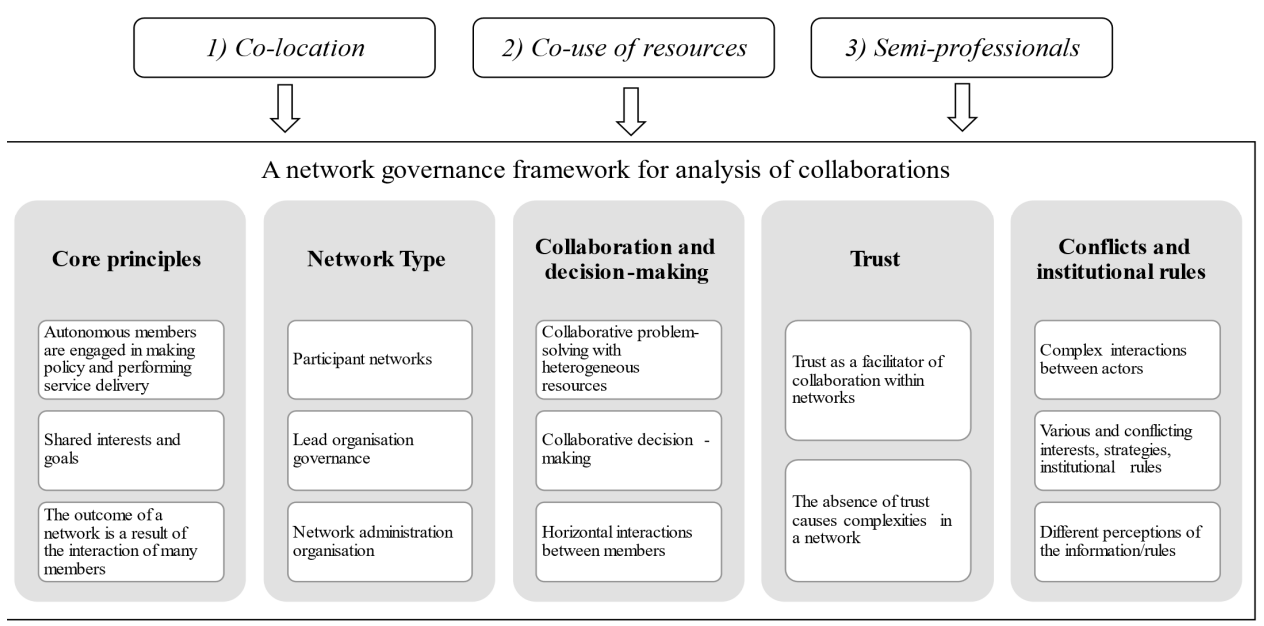

Since the emerging emergency response cross-sector collaborations are new and emerging, we have not found any studies focusing on cross-sector emergency response from a network governance perspective. Therefore, in this study, we will apply network governance as a theoretical lens for the cross-case comparison analysis. We reviewed about 20 scientific articles about network governance in order to formulate an analytical framework for this study. The articles were from the past four decades and their explicit focus was on how network governance has been defined and been used in research. Since network governance stem from different research traditions and has different application areas, we created a network governance framework which contains the core principles and those key factors of network governance that seem relevant for the analysis of the collaboration forms in this study. It will be used to explore cross-sector collaborations in emergency response if, and in what sense, they may be seen as network governance forms and, thus, whether the theory is usable when analysing and developing future collaborations. We have chosen to include the identified relevant key factors in Figure 1 (Jones et al., 1997; Powell, 1990; Klijn and Koppenjan, 2014; Weber and 
Khademian, 2008). Other key factor where identified but not included in the framework since they did not seem applicable to the current study. An example of a factor that has been excluded is 'network management' (Peters et al., 2017), which focuses on the internal mechanism of networks. Another is 'network performance' (Klijn and Koppenjan, 2014), which can only be assessed over the long term, not where the networks do not yet exist or are new (Peters et al., 2017). Also, we have not included ICT as a key factor since it does not recur in the existing literature (as a key factor) but we will pay attention to ICT in relation to the chosen key factors.

\section{Methods and materials}

In this section, we briefly describe the methods applied. For a more detailed description of the methods in the separate cases, see Yousefi Mojir et al. (2018) and Yousefi Mojir and Pilemalm (2014).

\subsection{Methodological approach: case study research}

Case studies seek to study actual social, organisational, or political phenomena (Stake, 2000). Accordingly, the case is understood through social construction and the meaning that people bring to the study object through various data collection methods. Case study research may include a single case or stretch over several case studies, relating to the same or similar phenomena, thus allowing for comparisons and conclusions on the transferability of the study results. Our study is carried out as a triple qualitative case study revolving around the same overall phenomenon: cross-sector collaboration in emergency response as an instantiation of public-sector network governance.

In the study, we focus specifically on three cases involving:

- co-location of professional response actors (e.g., the municipal rescue services and the police) and non-profit organisations (e.g., the Swedish Church) in the Safety House in Östersund, northern Sweden

- co-use of resources and collaboration between the rescue services, the social care unit and the technical division in Nyköping municipality, middle Sweden

- collaboration of the municipal rescue services with home care personnel, fire services day personnel, guards and technicians in Norrköping municipality, middle Sweden, in a study where semi-professionals were engaged as first responders.

This study is a merging and further development and comparison of the separate cases. The co-location case has been reported in Yousefi Mojir and Pilemalm (2014) and the semi-professional case in Yousefi Mojir et al. (2018). Two of the cases (co-location and co-use) has also been discussed conceptually as illustrations, from a perspective of implications for user-centred design in public sector innovation (Pilemalm et al., 2016). It should be noted that this is a qualitative study where the overall phenomenon explored is emergency response cross-sector collaboration. This means that we have not replicated the research design exactly in each different case (since they stem from different projects). However, we have used similar approaches for data collection in each case, relying to a great extent on interviews, workshops and a framework for template and data analysis. Also, since the study is qualitative in character the results from each separate 
case are not entirely comparable to the other cases. Rather, we try to identify key factors that either re-occur through the cases or that stand out in a specific case to be able to provide a knowledge base whose transferability can be tested by future research, as similar initiatives emerge. Finally, it should be noted that there may be a risk of potential cross-contamination of case 2 and 3 since they are somewhat similar and the involved municipalities are somewhat adjacent in time and place (the municipalities are situated about $50 \mathrm{~km}$ from the other). However, we deem the risk as low, except for the potential bias in the analysis performed by the researchers, which is present in all qualitative research. The co-location case is an own initiative from within the municipality while the case of semi-professionals is a research project and no municipality initiative. At the time of the study, initiatives in Sweden where largely local with little or no knowledge on what took place in other communities.

\subsubsection{Interviews and focus groups}

Interviewing is one of the most commonly used techniques for data collection in qualitative methods and case study research. In focus group interviews, it is possible to ascertain collective views on a particular phenomenon from a group of people who have interests, experience or knowledge concerning the topic in question (Myers, 2009). In all the cases, interviews lasting between 60 and 90 minutes were conducted with representatives from groups including project management, the municipal rescue services and the SOS Alarm national alarm centre. Additional focus groups of similar length were held in the third case. They included 13 representatives from four selected groups of semi-professionals, including both operative personnel and the managerial level from each respective group (Table 1).

\subsubsection{Scenario-based future workshops}

Jungk and Müller (1987) developed the original concept of Future Workshops as a technique allowing participants to reflect upon their current work situation and develop innovative ideas to enhance it. It has since been applied in various formats and application areas, not least as part of Participatory Design (Schuler and Namioka, 1993). In our study, full-day and half-day scenario-based Future Workshops were held in all three cases and involved representatives from the municipalities, the rescue services, SOS alarm, social care units, and various semi-professional groups (Table 1). In all cases, some of the workshop participants had also been involved in the interviews/focus groups. While Future workshops are a design technique rather than a method, it can be used for qualitative data collection, e.g., by asking about current situation, challenges and future needs, and documenting the data, as in our case.

\subsubsection{Experiment and after-action review}

In the case of semi-professionals, an additional experiment was arranged (Table 1). A car accident was simulated and two semi-professionals, along with the rescue services and the ambulance services, were sent on the response. The experiment had several purposes (e.g., measuring response times) but for this study, we observed the semi-professionals arriving at the incident site about 15 minutes before the professional resources providing first response. We then held an After-Action Review (AAR) with all the participants. 
AAR is a learning method, originating in the military domain that aims to capture and reflect upon the strengths and weaknesses of past events in order to improve future situations (Bolton, 2016).

Table 1 The three cases and data collection involved in each case

\begin{tabular}{|c|c|c|c|c|}
\hline Case & Interviews & Focus groups & Future workshop & Experiment/AAR \\
\hline $\begin{array}{l}\text { Safety House, } \\
\text { Östersund }\end{array}$ & $\begin{array}{l}4 \text { interviews with } \\
\text { project manager, } \\
\text { police, representative, } \\
\text { fire and rescue } \\
\text { services } \\
\text { representative, } \\
\text { Swedish Defense } \\
\text { representative }\end{array}$ & - & $\begin{array}{l}1 \text { workshop with } 8 \\
\text { participants from the } \\
\text { police, the municipalities, } \\
\text { the fire services and the } \\
\text { Swedish Defense }\end{array}$ & - \\
\hline $\begin{array}{l}\text { Co-use in } \\
\text { Nyköping }\end{array}$ & $\begin{array}{l}3 \text { interviews with } \\
\text { representatives from } \\
\text { fire services, social } \\
\text { care unit and facility } \\
\text { services }\end{array}$ & - & $\begin{array}{l}1 \text { workshop with } 10 \\
\text { participants from the fire } \\
\text { services, the social care } \\
\text { unit and the technical } \\
\text { division/facility services }\end{array}$ & - \\
\hline $\begin{array}{l}\text { Semi- } \\
\text { professionals } \\
\text { in Norrköping }\end{array}$ & - & $\begin{array}{l}4 \text { focus groups with } \\
\text { a total of } 9 \\
\text { representatives } \\
\text { from guard } \\
\text { company, home } \\
\text { care personnel, } \\
\text { facility services and } \\
\text { fire services day } \\
\text { personnel }\end{array}$ & $\begin{array}{l}1 \text { workshop with } 8 \\
\text { representatives from the } \\
\text { fire services, the } \\
\text { municipality, the police } \\
\text { and the healthcare sector } \\
1 \text { workshop with } 4 \\
\text { representatives from the } \\
\text { fire service day personnel } \\
\text { and the fire services }\end{array}$ & $\begin{array}{l}\text { Experiment/AAR with } \\
2 \text { semi-professionals } \\
\text { (fire services day } \\
\text { personnel), } 1 \\
\text { representative from the } \\
\text { fire services and } 2 \\
\text { representatives from the } \\
\text { ambulance services }\end{array}$ \\
\hline
\end{tabular}

\subsubsection{Data analysis}

A data analysis approach based on thematic analysis was applied in each case. All the interviews and focus groups were audio-recorded and transcribed. The future workshops and experiment/AAR were documented using post-it notes, memory notes, and audiorecording of the AAR. The thematic analysis evolved in an iterative process around themes that were successively identified as relevant to the emerging collaborations. A conceptual framework including the categories: Type/Role, Attitude, Training, Background, Task and Responsibility, Availability/Accessibility, Incident Type, Communication Method, Information Technology, Emergency Supplies, Organisational Structure, Leadership, Costs/Benefits, Environment, and Regulations and Legal Issues was used as support (Yousefi Mojir and Pilemalm, 2016). Opportunities, challenges and related needs were then identified in relation to each theme. In the subsequent cross-case comparison, network governance was applied. A network analysis was first performed for each case but for the purpose of space, only the cross-case comparison is displayed in this study. Two researchers, including the authors of the study, have been involved in all the cases, in data collection and data analysis, and in the network governance analysis. Two additional researchers were involved in the case of the semi-professionals. 


\section{Results and analysis}

In this section, we first describe the three cases, then present the identified themes with their associated opportunities, challenges and needs in each case. We also characterise the cases as various forms of cross-sector collaboration and relate them to the core principles of network governance and relevant key factors.

Co-location in Safety House in Östersund: Jämtland is a sparsely populated province in mid-Sweden with a population of about 112,000 . This population trebles during the summer season because of tourism. The 'Safety House' building is located in the province capital, the city of Östersund. Both professional response organisations and other organisations supporting or having responsibilities for response operations reside at the Safety House. Examples include the municipal rescue services, the police, SOS Alarm, the Swedish Defense, the Church and several authorities; for example, the County Board of Jämtland. The co-location arrangement is designed to improve alarm management in order to reduce the dispatch time of professional response resources by improving collaboration between actors, allowing actors to quickly gain a common understanding of the emergency situation, and creating a platform and citizen-centred service for shared information management and the disseminating of information to the public. The main characteristics of Safety House are thus inter-organisational collaboration among professional response organisations. However, they also include elements of cross-sector collaboration in that the defence sector and non-profit sector (the Church) are part of the co-location and also because it aims to involve civil citizens.

Relating this to the core principles of network governance, the organisations are still autonomous in the new setting and have their own organisational rules. They share interests and goals, i.e., reducing response time, providing a more effective response and reaching a shared understanding of the situation. Therefore, it is possible to consider the collaborations as an instantiation of network governance in the form of participant networks governance (Antivachis and Angelis, 2015). This is also reflected in that the participant organisations have received no regulation of mandates, no joint or common training or equipment. Rather they are supposed to build their network collaboration on routines existing in respective organisation. The same goes for ICT applications. Those in use at the time of the study (2012) included mostly stationary (non-portable) tools; for example, an alarm management system and a map system. Communication between actors took place via e-mail, telephone and mobile phones. Some actors also had RAKEL, which is a shared radio-based platform for communication among response organisations. The ICT applications had not been designed specifically for the new collaboration/co-location setting but were basically the same as those the actors were using before entering this collaboration, also when they were shared/used for collaborative purposes.

Co-use of resources in Nyköping municipality: Nyköping is a municipality in the middle of Sweden, about $100 \mathrm{~km}$ south of the capital, Stockholm, and with a population of approximately 55,000. In Nyköping, the fire and rescue services, the social care division and the municipality facility services are co-located in the new fire station. They also share certain vehicles, equipment and technologies in order to reduce costs. Both personal security alarms and automatic fire alarms are located at the fire station so as to be managed more efficiently by social care operators. At the time of the study (2014), the fire services still performed the response operations, but they sometimes requested 
support or information, such as exact addresses or keys to buildings. As the collaboration progressed, the facility services were also expected to become involved in the project and the related alarms (e.g., water damage to streets, elevators breaking down in the municipality's properties) and the social care night patrols were planned to be dispatched on some medical alarms.

Nyköping displays public-sector cross-sector collaboration as its main characteristic, focusing on the pooling of resources. However, even if Nyköping also embraces the vision of creating a safer society with its citizens in focus, the collaboration was mainly based on economic motives and efficient use of resources. From a network governance perspective, it is also possible to see the collaboration as a form participant networks governance, even though the division of tasks is somewhat more marked than in the case of Safety House. But also in Nyköping, there were no top management mechanism or mandate to control the collaboration. Rather, none of the organisations had priority over others, and they collaborated in a network governance pattern when necessary. Certain equipment was shared but not accompanied by common training. Also, the involved actors did not have ICT applications developed specifically for the new collaboration but used the existing systems of alarm management, with separate systems for each organisation. For communication they used e-mail, telephone and mobile phones.

Co-operative use of resources in Norrköping municipality: Norrköping is a municipality in southern Sweden with about 140,000 inhabitants. Here, emergency response cross-sector collaboration is not yet established, but between 2015 and 2017, a project was carried out in preparation for the collaboration. It was supported by participation from the municipality and its fire and rescue services and was based on the concept of the co-operative use of resources. The project was intended to identify, train, equip, dispatch, and evaluate potential resources, semi-professionals, who included facility services, taxi drivers, security guards, fire services day personnel, and eldercare personnel. Semi-professionals' primary jobs are not first response, but they do have competence (e.g., medical) or equipment that is useful and often patrol the community, thus being closer to emergency sites than professional response resources. Semi-professionals will be alerted simultaneously with the fire services and are free in certain, but far from all, decision-making at an emergency site. They are also restricted in performing certain actions to protect their own safety (e.g., smoke diving, managing explosive material) or by the law (e.g., giving medicine to victims).

The Norrköping study explores the recent trend in cross-sector collaboration of using entirely new occupations as first responders, and also involves various groups from the private sector (security guard companies) in the collaboration. Potential groups of semi-professionals have their own organisations and associated rules. Their regular tasks are sometimes, but not always, similar to those of first response. The fire services and semi-professionals share interests in saving lives and helping others in emergencies. In network governance terms, it is possible to view the collaboration as being of the type 'lead organisation governance' (Antivachis and Angelis, 2015). However, as we will discuss later on, it probably makes more sense to consider it as a hybrid form of network governance and more hierarchical government forms. This, since the semi-professionals will receive their training and guidelines from the fire services. Their actions are thus influenced by the fire services' regulation mandate in a top-down manner and they are not to be considered as independent and autonomous actors in the new collaboration. Training is also provided in a top-down manner rather than joint training among rescue 
services and semi-professionals. At the time of the study, semi-professionals did not have any ICT tools to support the emerging collaboration. There was also no fixed method for communication between actors. However, the project aimed to develop a mobile app prototype for the semi-professionals to enable them to receive alerts and be dispatched to the incident site.

\subsection{Theme: responsibility, availability and attitude}

Several opportunities related to the use of heterogeneous resources and competencies (Jones et al., 1997) can be identified in our studies. The interviewees and participants in the Safety House Future Workshop all confirmed the potential of their new work environment, in that the shared and facilities enable more comprehensive collaboration, exchange of information and collective solutions. In network governance terms, the co-location of actors was thus deemed to facilitate communication, collective problem-solving and horizontal collaboration (Powell, 1990; Klijn and Koppenjan, 2014), all designed to gain a shared understanding of emergencies.

In Nyköping, the interviewee from the fire services saw their organisation as resource intensive but not adequately utilising current resources:

"We pay 33 part-time firefighters in four municipalities, but we do not use them in an efficient way compared with the police, who have six resources in the same area."

Similarly, the interviewee from the social care division pointed out that their 30 staff often work on patrol and can, for example, help the police to report an event or hand keys to the rescue services. The interviewee from facility services mentioned providing lifting assistance, and intervening in incidents of damage to properties, streets, parks and ports. Participants in the Future Workshop argued that municipal alarms can be managed completely from within the joint alarm centre, including camera surveillance and burglar alarms. Thus, actors at the new fire station in Nyköping municipality also pooled their resources and competencies to help each other. However, in this case it seemed that economic motivations in terms of cost reduction played a more important role than the collaboration itself.

In Norrköping, the interviewees were in general positive about the potential new role of semi-professionals, regarding it as both individual development and an organisational bonus. With the exception of home care, they agreed that, if they received an alarm, most of the time they would be able to interrupt their current tasks and leave within about five minutes. Opportunities included being on patrol during day-time (home care) or at night (security guards), and the pooling of cars. Potential tasks at the emergency site included stopping simple bleeding, performing CPR, calming down shocked people, dispersing onlookers, extinguishing smaller fires, putting warning triangles on the road, and putting injured individuals in the recovery position. The opportunities identified in the study, from a network perspective, are thus most notable in relation to the pooling of resources, since the number of potential semi-professionals is much higher than that of professional resources and they are often spread across the entire municipality. This implies that creating a network by involving them would create a pool of huge capacity and resources to use in emergency response and might promote collective problem-solving.

The major identified challenges in all three studies were ambiguities in actors' roles, responsibilities and tasks in response operations. Actors at the Safety House had joint 
meetings to manage emergencies and made decisions based on mutual discussions. However, representatives at the Future Workshop identified a lack of clarity as to who/which response organisations can command the others and said that there is no available documentation concerning related decision-making. This can be related to network government incentives for democratic decision-making (Klijn and Koppenjan, 2014), indicating ambiguities and a need for greater formalisation in the new setting.

In Nyköping, the representative from the fire services expressed concerns as to:

"Who is responsible (and for what) when performing a response operation with the social care division or other actors? How many new tasks can one take on while simultaneously doing the regular work?"

It is also somewhat unclear as to who is responsible for the joint work environment when the fire station is shared, raising primarily financial and management questions. In the Nyköping fire station, actors did not interfere in each other's work but took decisions together in certain situations as needed. But nevertheless, there were sometimes conflicts in decision-making, about budget allocation and management processes that could potentially become an obstacle to collaborations/networking.

In Norrköping, similar concerns about ambiguities when prioritising among ordinary and 'first response' task were expressed, both by the interviewees from the facility services and the home care personnel:

\section{"[...]while fixing a big water leak at a school [...], we might receive an alarm about an accident nearby. To leave the school would lead to very big damage but of course if it was a matter of life and death you'd need to attend to it [the accident] first. But there can be complications." \\ "You may think that it's easy to interrupt a stroll [to go and help others in an accident], but it's not possible to just leave an elderly person [client] in the street and walk away."}

The semi-professionals also expressed uncertainty and sometimes fear about acting as first responders, not being able to manage the situation, making a wrong decision and putting people's lives in danger (e.g., moving a person with a neck injury). The interviewees from fire services day personnel also claimed that being semi-professionals might be stressful, knowing that at any moment you might suddenly receive an alarm. This may prevent people from being able to perform their new tasks correctly and be harmful to themselves or others. Relating the challenges of semi-professionals to network governance democratic decision-making, their autonomy is more restricted than in the other studies. They cannot replace and do not have the same scope for action as the fire services in emergencies, over who administrates the collaboration and who has decided the range of semi-professional tasks and responsibilities. In some critical situations, they need to wait for professionals. At the same time, this has the consequence that semiprofessionals have to choose their main tasks and may not act as first responders if they come into a situation where they need to prioritise.

As to needs, all actors at the Safety House Future Workshop saw the need to formulate and document the roles and responsibilities of actors and the hierarchy of different actors and command structures. In Nyköping, the needs similarly concerned roles, responsibilities, priorities and tasks; for example, having a reasonable workload in the new setting, clear mission goals, and related established knowledge among the different parties. In Norrköping, the identified needs again concerned clearly defined 
expectations and responsibilities for the semi-professionals, including defined tasks at the emergency site; but also that there should be support to help them handle potential stress, and emotional or psychological consequences. Interviewees from the fire services day personnel said they would feel safer if two semi-professionals worked together. The interviewees from the facility services claimed that a higher salary might encourage some personnel to take part in emergency response, while the other groups felt this would not be a good way to motivate people. Again, taking the network governance perspective, some of the main identified conflicts in network governance include conflicts of interests and strategy, perceptions of information and problems by members, and institutional rules, mostly because of the lack of a formal governing mechanism (e.g., Klijn and Koppenjan, 2014; Weber and Khademian, 2008). The studies display similar challenges but in various forms and degrees. However, they share the need for some kind of steering mechanism to govern the emerging collaboration.

\subsection{Theme: organisational aspects: laws, regulations and work environment}

As to opportunities, all Safety House participants agreed that regular formal and informal meetings and social contacts between actors had increased their knowledge about each other's organisations, their tasks and skills. This knowledge might lead to better trust between actors and was considered an important factor in collaborations:

"The fact that the Safety House has done it this way [to share facilities] has resulted in me knowing people in all the sections available here, including SOS, the police and ambulance services. I know exactly who I should call if I need to collaborate with someone."

The interviewees from the police and the fire and services emphasised the positive role of receiving feedback about completed response operations in the aftermath meetings from the respective actors who had participated. In the Nyköping Future Workshop, all participants believed that shared cars and premises had reduced costs and created better communication between actors. They also said that the centralisation of municipal alarms had worked well and that essential money could be saved in this way. Trust is usually discussed as a key factor, a central coordination mechanism and a facilitator (e.g., mutual interests and goals) or hindrance (e.g., inhibiting information exchange) for collaboration within networks (Klijn et al., 2010). According to the results, the co-location of actors in Safety House and the new fire station in Nyköping seems to have increased trust between actors because they have better opportunities (e.g., informal meetings, nearby offices) to get to know each other. In Norrköping, the interviewees saw no need to change their current work setting as long as the numbers of alarms are relatively few and, according to the management-level interviewees, there is no formal organisational obstacle, regulation or law to prevent them from acting as semi-professionals in emergencies:

"Of course, if there is an accident or injury where we can help, surely we can dispatch our resources, it is possible for us and it does not feel strange at all to me."

As to challenges, in Safety House, the issue of information confidentiality was identified as a major problem that inhibited the sharing of information (e.g., pictures, movies, documents) between different actors: 
"We [the fire services] have a confidentiality rule, the county council has another confidentiality rule [regarding ambulance services] that's a bit stricter than ours, SOS has its confidentiality and the police its own. Here, we have at least four different confidentiality laws that steer collaborations."

Other reported challenges included very limited and informal feedback on their work and response operations. In Nyköping, the interviewee from facility services said that privacy is not a big problem for them because they generally deal with alarms in which the information does not need confidentiality. The interviewee from the social care division on the other hand saw confidentiality as a key problem and the participants in the Future Workshop agreed that it is a common problem when different actors collaborate and share information. Furthermore, the difficulty of calculating the costs and benefits of the emerging collaborations was emphasised both by the interviewee from fire services and by participants in the Future Workshop:

"It's very difficult to calculate costs and benefits. It's mostly in theory that you can do it."

In other words, when insufficient information exchange, inhibiting a shared understanding of situations or preventing resource sharing, occurred at Safety House and in Nyköping this did not seem to have to do with a lack of trust between parties but more with confidentiality matters.

In Norrköping, there was a perceived lack of clarity as to what the consequences would be, not least in terms of insurance coverage, if a semi-professional is harmed at an emergency site or unintentionally harms another person; for example, a victim. Several representatives also pointed out that there are not any particular laws at the organisational or national level concerning these new cross-sector collaborations. From a network governance perspective, the identified ambiguity in supportive laws and the lack of insurance can be related to conflicting, or even absent or insufficient, institutional rules. From an ethical point of view, some interviewees from home care and the fire services day personnel were not comfortable with being continuously positioned by a dispatch system. Interviewees from facility services and the fire services day personnel claimed that traffic rules are not clear when they are driving their car to save somebody's life. For example:

"I think it's a bit stressful [...] You know that you're on your way [to help a dying person] but you can't exceed the speed limit."

As regards needs, those identified at Safety House were related to the secrecy issues and concerned aspects like the identification and handling of legal issues and potential obstacles. The police and fire services also noted the necessity of involving other actors, such as the municipalities and the County Administrative Board, in regular meetings. All participants pointed out the need to involve other actors who have local knowledge and may be used as volunteer resources; for example, the non-profit organisation 'Missing people', the Swedish National Home Guard, and civil citizens. Another need identified by all Future Workshop participants was a steering group to handle internal feedback and questions from the authorities and citizens, thus once more emphasising the need for steering mechanisms:

\footnotetext{
"Now we've grown, developed and we're so complex that we need an official group/function that can drive issues ... we can't answer all development queries and feedback internally because of the limited resources we have. It's an obstacle to development." (Police representative)
} 
In Nyköping, as well as the perceived need to address the secrecy issues, the participants in the Future Workshop argued that they should revise decision-making methods because decisions are based on old principles and agreements, thus again addressing the need for improved decision-making and steering mechanisms. An important example is how to allocate money and budgets to the co-located organisations. They also pointed out the lack of a forum where involved actors can sit down and talk about what they can do together, answer various issues and discuss new ideas and ways of interacting.

As to Norrköping, the identified needs concerned clarification of roles, tasks and responsibilities, legal and ethical aspects such as what semi-professionals are allowed to do, how they should deal with alarm information, and what kind of insurance they need. Again, this can be related to ambiguities in, or the absence of, adequate institutional rules. The interviewees from facility services mentioned the need for a system by which they can inform their managers that they have left their current workplace. Similarly, their manager said that they need to know the amount of resources and time their employees should spend as semi-professionals. The interviewees from home care and the fire services day personnel also said that it is important that other people inside the organisation know about semi-professionals' responsibilities. Otherwise, they might be questioned by their colleagues; for example, if they fail to do something or if the people they tried to help die. In network governance terms, this can be related to a lack of culture within their organisation about being semi-professionals. Semi-professionals mentioned their trust both in each other and in relation to the professional response organisations. At the same time, some of them did not have full trust in taking part in the collaborations due to ambiguities in the involved goals and how to prioritise between first-response tasks and ordinary tasks. The home-care personnel thus expressed a need to create internal trust in their own organisation/employer, rather than among the network participants, so as not to create internal suspicion about their new assignment.

\subsection{Theme: training and emergency supply}

As to opportunities, at Safety House, the interviewees from the police and the fire services mentioned that they had gained basic knowledge about each other's organisations, the new collaborations and information exchange through work-related education, feedback exchange between actors and informal meetings, leading to increasing trust between actors and facilitated collaborations. In Nyköping, the participants in the Future Workshop said that staff in social care and facility services receive 'municipal training' in risk management, fire and healthcare, and learn how to act in different situations. In the case of the Norrköping semi-professionals, most of the interviewees said that they had received some training in CPR, and some also in basic firefighting as part of their current employment contract. Interviewees from home care knew that some of the home care personnel had training as assistant nurses. Security guard interviewees pointed out that they had been trained, to some extent, to act as first responders. Interviewees from the fire services day personnel mentioned that a few of them have previously worked as firefighters or fire engineers. Regarding equipment, all the interviewees except home care said that they have cars with equipment; for example, first aid kits and fire extinguishers. Home care interviewees said that they have digital keys with which they can easily open their clients' apartment doors.

As regards challenges, the Safety House interviewees from the police and fire services mentioned the difficulties of applying the knowledge they had gained about the 
new collaboration to their practical work. As an example, the police are trained in the area of information confidentiality and what should or should not be shared with others. However, in their daily routines, the personnel did not exchange sufficient information about response operations because of the false understanding that all information is confidential. Thus, from a network governance perspective, the lack of training can once again be related to insufficient knowledge about relevant institutional rules and information handling, rather than not trusting each other.

In Nyköping, the interviewee from the fire services and the Future Workshop participants agreed that there is currently no dedicated training focusing on the cooperative use of resources or co-location of actors. In Norrköping, the semi-professional interviewees mentioned the difficulties of applying previous training because they had forgotten it, had not repeated it, or would not dare to use it in real situations. The manager of facility services claimed:

"[...] it's fresh the first year; however, then you start to forget. [...] we have training in CPR and similar types every four years but, as I said, it's not sufficient if we're expected to help in this way."

Even though all the interviewees acknowledged that they had already received some training, this was not always true for other employees working in their organisation. Regarding equipment, interviewees from the security guards and facility services said that their cars did not have much space to locate additional emergency supplies. The manager interviewees said that some equipment (e.g., defibrillators) is expensive and additional training is needed to use it properly.

In terms of related needs, in the Safety House Future Workshop, methods for transferring theoretical training/knowledge about the new collaboration into practice in terms of simulations and exercises were requested. Regarding confidentiality, there was a need for regular education to inform people about the correct handling of information and correct restrictions on information exchange between actors:

"We thought it [confidentiality] was a bigger problem than it really is. We received training and could find good ways to not break the confidentiality rules while communicating." (Project manager)

In Nyköping, training about the new roles was requested by the fire services:

"You should also receive training and knowledge about each other's roles to be able to have a better interaction. As an example, when actors have shared tasks, sometimes an actor may not intervene in an emergency because the actor may think that another actor is going to intervene and solve the problem and that is because roles and responsibilities are not clear."

The interviewee from facility services also believed that education is sometimes important when, for example, responding to alarms. However, this interviewee did not think the training for new tasks had the same importance for them:

"In many cases and situations, it is handwork that is needed."

The interviewee from the social care division and the Future Workshop participants believed that training for alarm management and the categorisation of alarms is central when invoking on-call resources. Joint training can also be a part of creating consensus about the new collaborations and the benefits of, for example, creating common interests and goals within the networks. As to hands-on equipment supporting the collaboration, the interviewee from the fire services mentioned RAKEL, ${ }^{1}$ mobile phones, computers 
and physical offices as most important. In Norrköping, the training needs of the semiprofessionals concerned updated training in CPR and basic fire extinguishing at least once a year, and practical exercises with the professional resources. The interviewee from the fire services day personnel also mentioned a need for training on traffic rules to act appropriately in traffic accidents, in managing shocked persons and injured relatives, and familiarity with routines relating to professional resources. The fire day personnel representatives highlighted more advanced training on managing suicide cases and traffic accidents, as well as how to use the alarm management systems and perform risk assessment. In terms of equipment, their needs were basic and concrete, and included dedicated smartphones for receiving alarms, blankets, reflective vests, warning triangles, pocket breathing masks, warning lights, defibrillators, extinguishing grenades and car chargers for mobile phones.

\subsection{Theme: information technology and communication}

As to opportunities, at Safety House both interviewees and workshop participants claimed that real life face-to-face communication before a response operation often leads to a more accurate interpretation of an incident and that relying solely on digital data, such as emails and digital records, may not be as effective. On the other hand, both at Safety House and in Nyköping, the majority of respondents emphasised the usefulness of the RAKEL communication system by which they could talk to each other using a shared platform, individually or in groups. The RAKEL coverage in the Safety House area is more extensive in comparison with the generally limited coverage of mobile phones in forests and mountains. In Nyköping, the social care unit argued that the use of RAKEL has already shortened the response time for the personal security alarms and has simplified the positioning of night patrols. The interviewee from the fire services mentioned email and telephone as the main communication methods for sending response operation reports. However, all the semi-professionals in Norrköping emphasised their preference for using smartphone-based solutions for receiving alarms, communicating with others, and taking photos of the emergencies. Interviewees from home care and the security guards said that they already receive work-related alarms concerning urgent events on their mobile phones and would prefer to continue using the same devices. The security guards also already had extra equipment for communication, such as handheld PCs.

As regards challenges, not all actors at Safety House had RAKEL since it is expensive and not affordable/prioritised by some organisations, which thus have to rely on mobile phones. In Nyköping, the facility services said they do not have RAKEL because it is too expensive. Also, in Norrköping, the semi-professionals claimed that, in a purely mobile-phone-based system, network coverage might be inadequate in some areas such as forests, rural areas, and the basements of buildings. For example, the interviewee from facility services said:
"[...] one problem can be when you are in the basement of buildings or are working in some underground centers $[\ldots]$ and there is no mobile phone coverage. This can be a problem since you spend a lot of time there, at least I myself often work in underground centers."

The Safety House interviewees from the fire services and the police mentioned that it was difficult to access other actors' information (e.g., their position or their status), or their 
information about an incident. Regular meetings and face-to-face conversations are not deemed sufficient in larger emergencies involving more information and many response actors. Difficulties with information exchange were discussed in the Future Workshop because actors might not know exactly what kind of information is needed by other actors. The interviewee from the fire services mentioned difficulties in viewing and browsing information from the incident site due to the absence of more sophisticated ICT, especially mobile tools. Moreover, not having sufficient communication channels to exchange information with the public had inhibited one of the main aims of Safety House, to provide a citizen-centred service. In Norrköping, several semi-professional representatives pointed out that more comprehensive information systems are not an important part of their current job and that they do not have their own system (e.g., an alarm management system or positioning system) that can be used in their new tasks.

As to needs, those identified at Safety House included a shared platform for communication and data exchange in response operations that would facilitate a shared understanding of a situation, and an information system that provides a facility for actors to share maps and other visual and spatial information. The interviewee from the Swedish Defense also mentioned the potential usefulness of an integrated system for exchanging information with other actors located physically outside the Safety House. The interviewee from the fire services mentioned the need for sophisticated portable tools to view, analyse and disseminate information; for example, portable digital maps. Participants in the Future Workshop suggested a document management system to both facilitate incident information seeking and learning from previous experiences (feedback). In Nyköping, the most important identified needs included a joint alarm management system, IT support displaying the geographical location and a map of the emergency site. Others concerned digital channels to the public and support to extract relevant statistics from existing data. A future shared platform for accessing information was deemed important. Being able to document directly in the night patrol using IT was a key requirement of the social care division. In the Future Workshop, participants thought that a joint forum for thoughts and ideas could simplify the development of new collaborations.

As regards the semi-professionals in Norrköping, all the interviewees emphasised the need to talk to the alarm centre and the professional resources in case they need to receive more information. They also requested a dedicated ICT application for receiving alarms that could be integrated with their current mobile phones. The system should provide short but precise information about the type of incident, its location, a brief description of the incident, a navigation function, and information about when professional resources would arrive. The interviewees from home care mentioned the possibility to easily send information (video, photos, text) relevant to emergencies to the alarm centre or the fire services. Interviewees from the fire services day personnel and home care highlighted the need for an acknowledgement function by which semi-professionals can inform others that they are at the emergency site and for a function by which they can inform the alarm centre whether or not they are available. In the Future Workshop, an additional set of functions were identified; including to support report back after the response operation, to automatically inform their employers about interrupting their current task, and a status function by which a semi-professional can inform others (e.g., the alarm central) when he or she is on the way, has arrived or needs extra help. Quick checklists about what a semi-professional should do in a specific emergency were also identified as helpful. 


\subsection{Network governance analysis summary}

The results and analysis indicate that emerging forms of collaboration in Swedish emergency response in many respects resemble but also differ from more traditional network governance patterns, in that they display a hybrid form of governance and government. A main finding is that all three studies uncovered a distinct need for steering mechanisms, the clearing of responsibilities and agreements. Much more distinct than has been reported in governance networks based more on informal, dynamic interactions among members. In the cross-case comparison, it was also notable that this need increases with the cross-sector character of the collaboration and the heterogeneity of the involved actors. Safety House, which is currently more of an inter-organisational than a pure cross-sector collaboration, most resembles traditional network governance structures based on shared interests. The Nyköping municipality's on-going cross-sector collaboration also resembles network governance in many respects, but is more based on economic incentives than shared interests and displays a larger complexity in terms of such aspects as power, responsibilities and task prioritisation. The semi-professionals in Norrköping, who embrace cross-sector collaboration both within the public sector itself and with the private sector, involving entirely new occupation groups as first responders, display the most complexity and can be characterised as the most hybrid form of governance and government. Their cross-sector collaboration takes place in a more hierarchical decision-making pattern than a pure network governance structure. An additional explanation for the complexity and substantial need for steering mechanisms is that, here, the collaboration concept has not yet been implemented and thus the tasks are not defined.

More specifically, the cross-sector collaborations fit comparatively well into an overall network governance framework in terms of institutional perspectives, most notably in the identified themes 1 and 2. This includes the key factors of shared interests, collaboration between heterogeneous autonomous actors, democratic decision-making, the importance of trust and related conflicts in collaborations and institutional rules. An example is when complexities in interactions between members of the Safety House relate to difficulties in decision-making in emergencies due to ambiguities about responsibilities and conflicts of opinion. In Nyköping municipality, related questions arose, such as "who is the main body responsible for the new shared environment?" and it was also possible to discern conflicts around the new budget allocation. A third example is when institutional rules in Norrköping are not only unclear but do not yet actually exist; agreements are not yet written, and existing laws are insufficient.

At the same time, there are also concrete key factors that enable - or hinder emergency response cross-sector collaboration, which falls outside the network governance institutional perspective; which is notable above all in relation to themes 3 and 4. One of these factors is the obvious need for education and joint training and exercises, discernible in all cases. Another is the need for basic equipment, relating specifically to the assignment of first response and thus most visible in the case of the semi-professionals. While Nyköping municipality spoke mostly about a need for office equipment, and basic equipment was available at the Safety House, the semi-professionals requested checklists, reflective vests, fire extinguishers, and defibrillators, among other things. The semi-professionals also mentioned fear and stress as a potentially key factor hindering collaboration, and requested trauma support. Finally, from these studies it is clear that ICT support should be considered a pre-requisite for the 
emerging cross-sector collaborations, even though this is not part of current network governance key factors. This includes GPS, mobile applications and decision-support systems for dynamic resource allocation, dispatching the new resources as enablers of the collaborations and, for instance, RAKEL as a facilitator (if existing and working) or hindrance (if too expensive and insufficient coverage).

The cross-case network governance analysis is summarised in Table 2.

At a more general level, it is notable that besides the absence of regulations of mandates, joint training and new IT to support the new collaboration in each case/collaborative space, within the time frame of the study, there was no inventory or reinforcement of structures, equipment and IT solutions across networks. We will return to this in Section 5.

Table 2 Comparison between network governance and emerging forms of collaboration in the three cases

\begin{tabular}{|c|c|c|c|}
\hline $\begin{array}{l}\text { Network } \\
\text { governance (NG) }\end{array}$ & Co-location & Co-operative use & Semi-professionals \\
\hline \multirow[t]{2}{*}{ Core principles } & \multicolumn{3}{|c|}{$\begin{array}{l}\text { Similarities NG: } \\
\text { - Heterogeneous actors with shared interests } \\
\text { - Collaboration between independent organisations with their own rules }\end{array}$} \\
\hline & $\begin{array}{l}\text { Differences to } N G \text { : } \\
\text { - Present need for steering } \\
\text { mechanism for } \\
\text { command/control and } \\
\text { decision-making }\end{array}$ & $\begin{array}{l}\text { Differences to } N G \text { : } \\
\text { - Present need for } \\
\text { steering mechanism for } \\
\text { decision-making and } \\
\text { budget allocation }\end{array}$ & $\begin{array}{l}\text { Difference to } N G \text { : } \\
\text { - Existing hierarchical control of } \\
\text { semi-professionals' actions }\end{array}$ \\
\hline \multirow[t]{2}{*}{$\begin{array}{l}\text { Collaboration and } \\
\text { decision-making }\end{array}$} & $\begin{array}{l}\text { Similarities to } N G \text { : } \\
\text { - Collaborative action and } \\
\text { problem solving. } \\
\text { - Democratic decision- } \\
\text { making }\end{array}$ & $\begin{array}{l}\text { Similarities: to } N G \text { : } \\
\text { - Democratic decision- } \\
\text { making } \\
\text { - Resource sharing and } \\
\text { collaboration in certain } \\
\text { alarms }\end{array}$ & $\begin{array}{l}\text { Similarities: to } N G \text { : } \\
\text { - Collaborative action and problem } \\
\text { solving }\end{array}$ \\
\hline & $\begin{array}{l}\text { Differences to network } \\
\text { governance: } \\
\text { N/A }\end{array}$ & $\begin{array}{l}\text { Differences to } N G \text { : } \\
\text { - Visible focus on cost } \\
\text { reduction which is not } \\
\text { common factor in } \mathrm{NG}\end{array}$ & $\begin{array}{l}\text { Differences to } N G \text { : } \\
\text { - Limited decision-making by semi- } \\
\text { professionals }\end{array}$ \\
\hline Trust & $\begin{array}{l}\text { Similarities to } N G \text { : } \\
\text { - Facilitator of collaboratio } \\
\text { - Can reduce institutional c } \\
\text { Differences to } N G \text { : } \\
\text { - Potential lack of trust ster } \\
\text { conflicts, and lack of trair } \\
\text { about confidentiality, not } \\
\text { each other's interests }\end{array}$ & $\begin{array}{l}\text { omplexities } \\
\text { ns mostly from ambiguity, } \\
\text { aing in institutional rules } \\
\text { from a lack of respect for }\end{array}$ & $\begin{array}{l}\text { Differences to } N G \text { : } \\
\text { - 'Internal trust' not discussed in } \\
\text { network governance }\end{array}$ \\
\hline
\end{tabular}


Table 2 Comparison between network governance and emerging forms of collaboration in the three cases (continued)

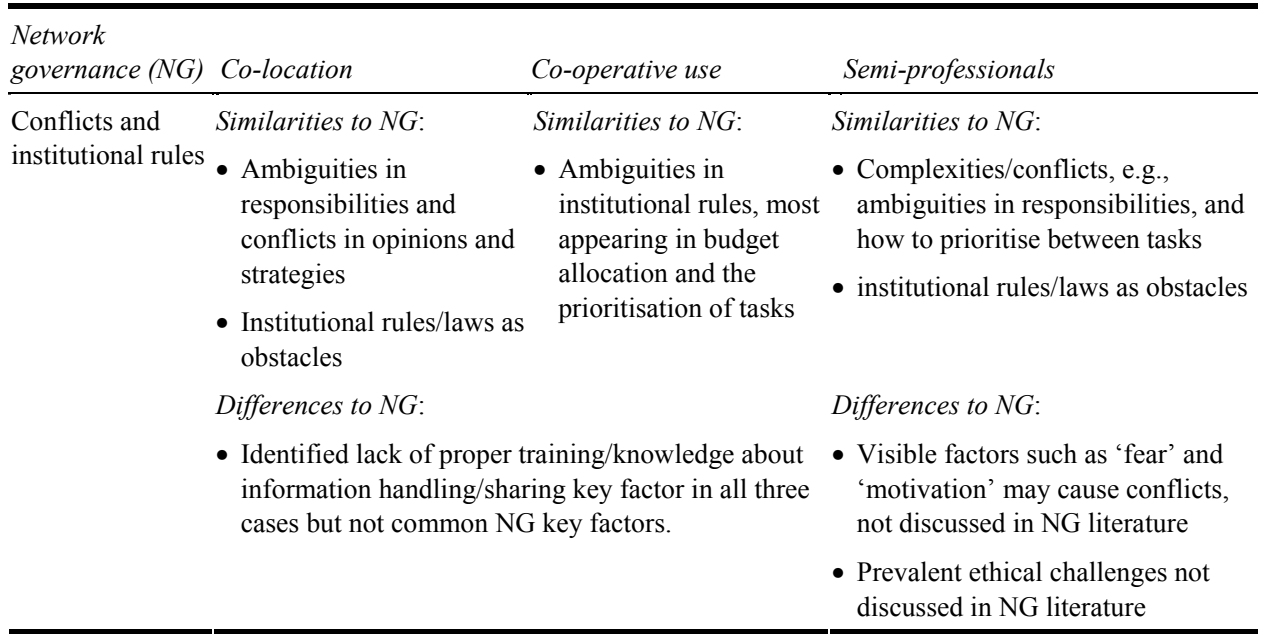

\section{Discussion}

In this section, we first discuss the results in light of the emerging need for emergency response cross-sector collaborations and IT as an enabler. We then discuss the potential usefulness of network governance perspectives when analysing and developing these emergency response collaborations. We end by including transferability of study results to wider public-sector cross-sector collaboration contexts.

\subsection{Emerging emergency response cross-sector collaborations and new research needs}

Public-sector cross-sector collaborations are global trends (e.g., Johnston and Finegood, 2015; Jones et al., 2015; Grudinschi et al., 2013; Alford and O'Flynn, 2012; Agranoff and McGuire, 2010; O’Leary and Bingham, 2009; Bryson, 2004). In the past decades, they have become important to emergency response (e.g., Barsky et al., 2007; Venema et al., 2010; Waugh and Streib, 2006), not the least in Sweden (e.g., Weinholt and Andersson Granberg, 2015; Pilemalm et al., 2013). Both natural large-scale disasters and man-made incidents, not least due to terrorism, have become increasing threats to our society at the same time as regular accidents on a smaller scale will continue to occur. The centralisation of resource-strained response organisations leading to long distances between residents and response organisations in sparsely populated areas is also likely to continue. This combination means that the professional emergency response organisations responsible for delivering essential services are often placed under extreme pressure while having to meet increased demands for efficiency. Since this trend is comparatively recent, corresponding research is needed. However, emergency response studies are seldom explicitly connected to cross-sector collaborations. Furthermore, they are quite fragmented and focus on a specific topic (e.g., techniques, human elements, teamwork, exercises). This study contributes in this respect, by providing knowledge 
from three different cases in Swedish cross-sector collaboration emergency response, identifying common opportunities and challenges, as a starting point for future research.

\subsection{ICT as an enabler of emergency response cross-sector collaborations}

Some of the organisational needs and challenges identified in this study are in line with previous literature. Studies on Swedish emergency response highlight difficulties in building trust and legitimacy, in gaining a shared understanding of incidents and insufficient categorisation of responsibilities, ambiguities about actors' needs, uncertainty in communication and a lack of incentives when involving other resources and creating networks (e.g., Yousefi Mojir and Pilemalm, 2016; Pilemalm et al., 2013; Berlin and Carlström, 2011; Palm and Törnqvist, 2008). When it comes to ICT, in the area of emergency response, the need for proper and optimised positioning of professional resources for faster response has been demonstrated in several technically oriented studies (e.g., Leknes et al., 2017; Andersson Granberg et al., 2016). Turoff et al. (2004) further identify the needs for systems training, accessing vital, up-to-date and correct information, and the free exchange of information. However, we believe that (also) when taking the cross-sector collaboration perspective, it is important not to separate organisational, structural and technical aspects of the collaborations but to view and handle ICT as an enabler of collaboration. This is also something that has been highlighted by Yousefi Mojir and Pilemalm (2016).

When taking a linear perspective, the study illustrates the fast evolution of technological development. Whereas Safety House (2012) and Nyköping municipality (2014) express future needs for mobile solutions, in Norrköping (2016-2017) the mobile solutions are already in place and part of the users' own existing applications. The ICT enablers include GPS, mobile applications, and decision-support systems for dynamic resource allocation dispatching the new resources. The major challenge, identified in the study, not the least in the case of semi-professionals, lies instead in re-configuring this ICT, adding cross-sector functions in line with identified needs and according to proper organisational structures, and matters of confidentiality, agreements and laws, when integrating the new technologies into those existing of professional response organisations.

Relating this to a larger public sector perspective, studies highlighting the significant role of networks, information sharing and resources, private-sector partnering, and public-sector cross-sector collaborations have been discussed under different names, including network governance, new public management, public-private partnerships, and e-government, as a potential solution to many public challenges (Agranoff, 2007; Waugh and Streib, 2006). While the studies of collaborations mostly take a political science perspective, they would probably not have expanded without access to modern ICT and the bi-directional influence of technology and governance has been noted in the literature for over a decade (Kling et al., 2003). In specific, there have been recent macro-level claims about the need to bridge the research disciplines of IS and political science, reflecting the recent proposed merging of digital government and public administration research (Gil-Garcia et al., 2018). In the area of e-government, it has been proposed that public policy-making and project management in the field of IS can be balanced and thereby reach a more sustainable outcome at this juncture (Melin and Wihlborg, 2018). In relation to practical IS development, the need for inter-disciplinary design teams for the cross-sector collaborations, including political science and juridical perspectives, 
has been suggested (Yousefi Mojir et al., 2016). This study thus not only supports the perceived need to bridge the overall gaps between political science and IS research perspectives. We suggest that a point of departure bridging the organisational and technical from the very beginning, and viewing ICT artefacts as enablers introducing new challenges, seems to be a necessity for developing emerging emergency response cross-sector collaborations.

\subsection{Cross-sector collaboration as network governance: capturing the institutional perspectives but missing out on ICT}

This paper contributes to the analysis and development of future cross-sector collaborations to help ensure that key institutional factors for success are enabled and hindrances reduced. In retrospect, we deem the network governance perspective useful in that it helped us to identify the key institutional factors relevant for emergency response cross-sector collaborations. Such identification is crucial as starting point for developing and improving the collaborations. At the very same time, the studied collaborations are generally more formalised than pure network governance dynamic patterns because they are more tightly coupled with the respective organisations' own contexts. This, in turn, requires more formalisation and steering mechanisms of the collaboration form than is usually the case in network governance networks. In other words, hierarchical governing mechanisms and regulations may need to supplement network governance mechanisms for cross-sector collaborations. In our study, we also identified a need for internal trust, which has rarely been discussed in network governance (to our knowledge and the overview of network governance literature in relation to this study), which rather focuses on trust among network organisation (e.g., Jones et al., 1997; Klijn and Koppenjan, 2014). This is not surprising given the nature of many network collaborations. However, including internal trust, i.e., trust from other actors (managers, colleagues in ordinary organisation or in the fire services) seems crucial to include when new occupations are to be involved in first response and thus have to switch among work tasks, role and organisational 'belonging'. Actors in all three studies seem having achieved this internal trust, which is likely to enhance the prospects for collaboration. However, there are other studies showing that many professional organisations do not trust resources from other sectors or volunteers in response operations (Jansson and Grip, 2016).

Based on the above, we thus believe that network governance may well be used but is not sufficient when capturing the institutional aspects of emergency response cross-sector collaborations. Complementary perspectives, including theories from policy networks (Carlsson, 2000) and new public management (Gruening, 2001), may be used to address the potential need for hierarchical governing mechanisms and regulations. There are also key factors or practical needs in the collaborations that cannot be captured solely by using a network governance perspective, most notably in the case of the semi-professionals, but that must be addressed when developing the collaborations. The fact that basic equipment and training/exercises play a specific role, given the emergency context, is not surprising. Somewhat more surprisingly, we have not found any descriptions of network governance including ICT as a key factor, in our literature overview even though IT support (e.g., as a facilitator of or hindrance to collaboration) should play an important role, not only in emergency response, but in any contemporary network governance context. This might have to do, with that network governance is usually applied from a public management or public administration perspective, thus again pointing at the policy science, public 
administration and IS research perspectives should complement each other (Gil-Garcia et al., 2018). There are also studies which take a more general government perspective and claim that multi-organisational collaboration must explore technical, organisational and governance aspects in parallel to enable ICT success. For instance, Dawes (2009) claimed that governance in an uncertain, digitalised future must encompass both technical and non-technical elements. Feldman and Horan (2011) studied a US nation-wide system for social security administration and found that privacy, security and agreement aspects of the system were challenges that the governance structures must handle for the system to be used and usable. Schooley et al. (2010) argue that reliable data exchange is crucial in the ICT in time-critical multi-organisational collaborations such as the medical emergency services, and that this requires inter-organisational relationships and governance mechanisms. Schooley and Horan (2007) argue similarly when taking an inter-organisational IT governance perspective and claim that lacking in the establishment of reliable and well governed ICT in time-critical public services, can, at times, lead to failure life critical endeavours. Translating these macro-level perspectives to network governance, we therefore believe that ICT as a key factor should be included as part of future network governance theory, and that this is of special importance when analysing emergence response cross-sector collaborations, which are indeed time-critical and of involves attempts to save lives. Our findings reflect the Janowski et al. (2012) meta-study of 12 cases on various networks all being enabled by ICT, and the recent discussion by Loukis et al. (2016) arguing "that network governance should be conceptualised as an evolving socio-technical process shaped by actors and aimed at tackling complex and dynamic contemporary challenges".

Taking this discussion one step further, we suggest that network governance analysis of, for example, cross-sector collaborations, could benefit from combinations of approaches and perspectives taken from the IS research field. One example is the sociotechnical ensemble view which and conceptualises IS as a package of people, tasks, devices, artefacts and policies, and which focuses on the interactions between people and technology, whether during construction, implementation, or use in social contexts (Orlikowski and Ianoco, 2001). The socio-technical ensemble view is a perspective rather than a theory, and while it has some overlaps with network governance, it is broader in scope, while remaining at a more abstract level and providing concepts, rather than explaining how to use them. Socio-technical ensembles may thus be used as a point of departure to ensure that aspects such as tasks, devices (here: equipment) and IT artefacts are included, and combined with network governance to concretise and focus the key institutional aspects that were central to, but mainly unsolved in, the emerging emergency response collaborations. In relation, it would be possible to argue that network governance is rather predictive in nature, while this study is mainly exploratory. However, we believe that a necessary first step is to explore whether a theory or perspective is suitable to address a certain phenomenon (here: emergency response cross-sector collaboration), and if it is, in the next step see to it that that associated key factors are handled in the collaborations.

\subsection{Study transferability and limitations}

The study is a triple case study on cross-sector collaboration in first response to smallscale, frequent emergencies in Sweden spanning from 2012-2017. As noted in the analysis section there were, at the time, no transfer of lessons identified, e.g., in terms of 
equipment inventory, need for joint regulations of mandates and joint ICT support across the cases. This is not surprising, given that cross-sector collaborations in emergency response was a new phenomenon, that two of the cases differed in both character and space (co-location and co-use) and the third case (semi-professionals) was a research project. Nevertheless, since all cases pointed at similar needs, this is something that should be, and is, to some extent, addressed by current emergency cross-sector collaborations. In terms of network governance, the cases in the study (co-location, co-use, semi-professionals) have been viewed as instantiations of a hybrid form or specific governance regime, i.e., emerging when occupations that previously did not work together perform joint collaborations. Of course, it is a limitation of study that only three cases were included. It is difficult to say whether they are transferable to similar emerging governance regimes, nationally and internationally. However, since the time of the study, in particular the concept of using semi-professionals, has spread in Sweden and involves for instance security guards. The mandates are regulated among the municipal rescue services and the security guard companies in work agreements. The security guards have access to the RAKEL communication system and overhear certain predefined alerts. Mobile android solutions (app) are also currently being developed by the Swedish Public Answering Point (PSAP) to connect the semi-professionals to the rescue services back-office system, allowing for their dynamic resource allocation and dispatching. Recent studies of semi-professionals actually being implemented as a crosssector collaboration or hybrid network governance form in Swedish emergency response point at similar present key factors (e.g., the need for steering mechanisms, mandate, trust, work agreements, task prioritisation) (Pilemalm, 2020). This indicates the transferability of the study findings at a national level. As for international applicability, more research is needed. Possibly, the emerging network forms with identified key factors are most applicable to countries with similar decentralised structures, regulations for confidentiality and legal systems as in Sweden where, for instance, the decision to engage in cross-sector collaborations reside at local level (e.g., with involved municipal rescue services). On the other hand, other more hands-on aspects of the emergency response cross sector collaborations (e.g., resources deployed, main tasks, life-saving goals, basic needs for equipment, training and IT support) tend to be similar in many countries.

Also, as to the potential transferability of the study results in a wider perspective they first refer, to emergency response of frequent accidents but also to comparing scale; i.e., routine accidents vs. large-scale crises and catastrophes. Quarantelli (2000) argues that, despite both quantitative and qualitative differences between everyday emergencies and large-scale disasters, research and development work in both types of emergencies can learn from each other. Large-scale crises are more demanding in terms of resources and more unpredictable than small, frequent accidents. The infrastructure and services in a society may become unavailable, and response operations generally involve a huge number of actors from different sectors, regions and even countries, in the form of 'mega communities' (Kleiner and Delurey, 2007). Nevertheless, similar resources, ICT, IS and equipment are often deployed. Also, we know that people (e.g., semiprofessionals) who are trained in, and have some experience of providing, first response in routine emergencies will be better prepared to act in large-scale crisis management, especially if they have already learnt how to use the technology employed. At a more general level, while various public-sector cross-sector collaborations have different aims, there are also similarities because the actors are from different sectors and have to 
collaborate within the frame of their respective organisations. In relation, clarification of the roles, practices, interests, and duties of involved partners is always needed. For example, Bryson (2004) argue for the complexity of the interaction between actors and the need for continuous trust building between them. Also, in a healthcare cross-sector collaboration involving both the public and private sectors, trust was found to be a key success factor (Johnston and Finegood, 2015). Therefore, other parts of the public sector are likely to benefit from parts of the results and can adapt them or use them as inspiration for their own cross-sector collaboration development. Of course, some sectors are quite similar to emergency response, whereas others are different. One potential example of the former is healthcare, in which dealing with patient care (compared with victim care) might include similar medical tasks, where the ambulance services are often involved, and where the same laws and regulations sometimes apply.

\section{Conclusions and future work}

Public sector innovation, transformation, and practice is highly relevant to emerging emergency cross-sector collaborations, in a society where crises occur frequently and where at the same time emergency response organisations need to continue their day-to-day first response in resource-strained environments. To our knowledge, this is the first study juxtaposing and comparing the opportunities, challenges and needs from several cases of emergency response cross-sector collaboration, and this should be seen as the study's major contribution. The major opportunities identified included shared facilities and equipment, and a positive attitude towards the new assignment/ collaboration. Major challenges included the undefined roles, responsibilities, and tasks of new actors in response operations, difficulties in prioritising among ordinary tasks and new tasks in resource-strained organisations, and a lack of legislation, routines and insurance. Needs related to improved and repeated training and joint exercises, and to trauma support and basic supplies; including blankets, reflective vests, warning triangles, and pocket breathing masks. IT suggestions included improved shared communication platforms, systems for errand handling, for the joint assessment of information, status and acknowledgement of available and dispatched resources, and smartphone-based alarm management. The study's cross-comparison network governance analysis suggested that emergency response cross-sector collaborations can be characterised as a hybrid form of government and network governance, especially when new occupations are brought in to act as first responders. The study here provides a theoretical contribution in arguing for the inclusion of IT as a key factor in network governance. It also discusses the potential benefits of combining network government analyses with perspectives from the IS field; for example, the socio-technical ensemble view.

Some possible directions for future work include exploring the potential co-use of new resources in ordinary accidents and large-scale crises. From a wider public-sector perspective, important future studies might include the development of methods and costbenefit models to evaluate emerging cross-sector collaborations. As to the connection of network governance and emergency cross-sector collaboration, future work may also incorporate other related theories; for example, public administration, new public management and policy networks theory. Also, the connection between the fields of IS and policy science research in areas of public policy-making, and on IS development and IS impact, will be interesting to explore, because they both affect future cross-sector 
collaborations. Finally, in line with the study limitations outlined above it would be, if possible, of great interest to compare and contrast the emerging cross-sector collaborations/network governance forms to similar initiatives in emergency response in other countries.

\section{References}

Agranoff, R. (2007) Managing within Networks: Adding value to Public Organisations, Georgetown University Press Washington, DC.

Agranoff, R. and McGuire, M. (2010) Collaborative Public Management: New Strategies for Local Governments, Georgetown University Press, Washington, DC.

Alford, J. and O'Flynn, J. (2012) Rethinking Public Service Delivery: Managing with External Providers, Palgrave Macmillan, Houndmills, Basingstoke, Hampshire, New York.

Andersson Granberg, T., Danielsson, N., Fredriksson, A., Nordström, J., Pilemalm, S., Tjernström, R. and Yousefi Mojir, K. (2016) 'Using semi-professionals in emergency response', ISCRAM 2016: Proceedings of the 13th International Conference on Information Systems for Crisis Response and Management, Rio de Janeiro, Brazil.

Antivachis, N.A. and Angelis, V.A. (2015) 'Network organisations: the question of governance', Procedia - Social and Behavioral Sciences, Vol. 175, pp.584-592, https:// doi.org/10.1016/j.sbspro.2015.01.1241

Babiak, K. and Thibault, L. (2009) 'Challenges in multiple cross-sector partnerships', Nonprofit and Voluntary Sector Quarterly, Vol. 38, No. 1, pp.117-143, https://doi.org/ 10.1177/0899764008316054

Barsky, L., Baumann, J., Torres, M. and Aguirre, B (2007) 'Managing volunteers: FEMA's urban search and rescue programme and interactions with unaffiliated responders in disaster response', Disasters, Vol. 31, No. 4, pp.495-507, https://doi.org/10.1111/j.14677717.2007.01021.x

Berlin, J.M. and Carlström, E.D. (2011) 'Why is collaboration minimised at the accident scene? A critical study of a hidden phenomenon', Disaster Prevention and Management: An International Journal, Vol. 20, No. 2, pp.159-171, https://doi.org/10.1108/ 09653561111126094

Bolton, F. (2016) 'Use of the after-action review to improve learning', Assessment Update, Vol. 28, No. 2, pp.3-15, https://doi.org/10.1002/au.30051

Brinkerhoff, J.M. (2002) 'Government-nonprofit partnership: a defining framework', Public Administration and Development, Vol. 22, No. 1, pp.19-30, https://doi.org/ 10.1002/pad.203

Bryson, J. (2004) 'What to do when stakeholders matter. Stakeholder analysis and analysis techniques', Public Management Review, Vol. 6, No 1, pp.21-53, https://doi.org/ $10.1080 / 14719030410001675722$

Carlsson, L. (2000) 'Policy network as collective action', Policy Studies Journal, Vol. 28, No. 3, pp.502-520, https://doi.org/10.1111/j.1541-0072.2000.tb02045.x

Chatfield, A.T. and Reddick, C.G. (2018) 'All hands on deck to tweet \#sandy: networked governance of citizen coproduction in turbulent times', Government Information Quarterly, Vol. 35, No. 2, pp.259-272, https://doi.org/10.1016/j.giq.2017.09.004

Dawes, S. (2009) 'Governance in the digital age: a research and action framework for an uncertain future', Government Information Quarterly, Vol. 26, No. 2, pp.57-264, https://doi.org/10.1016/j.giq.2008.12.003

Drezner, J.R.A., Heistand, J., Bloomingdale, M. and Harmon, K. (2009) 'Effectiveness of emergency response planning for sudden cardiac arrest in United States high schools with automated external defibrillators', Circulation, Vol. 120, No. 6, pp.518-525. 
Feldman, S.S. and Horan, T.A. (2001) 'Collaboration in electronic medical evidence development: a case study of the Social Security Administration's MEGAHIT System', International Journal of Medical Informatics, Vol. 80, No. 8, pp.127-140.

Gazley, B. and Brudney, J.L. (2007) 'The purpose (and perils) of government-nonprofit partnership', Nonprofit and Voluntary Sector Quarterly, Vol. 36, No. 3, pp.389-415, https://doi.org/10.1177/0899764006295997

Gil-Garcia, J.R., Dawes, S.S. and Pardo, T.A. (2018) 'Digital government and public management research: finding the crossroads', Public Management Review, Vol. 20, No. 5, pp.633-646, https://doi.org/10.1080/14719037.2017.1327181

Greve, C. and Hodge, G. (Eds.) (2005) The Challenge of Public-private Partnerships: Learning from International Experience, Edward Elgar, Cheltenham, UK, Northampton, MA.

Grudinschi, D., Kaljunen, L., Hokkanen, T., Hallikas, J., Sintonen, S. and Puustinen, A. (2013) 'Management challenges in cross-sector collaboration: elderly care case study', The Innovation Journal, Vol. 18, No. 2, Article 7.

Gruening, G. (2001) 'Origin and theoretical basis of new public management', International Public Management Journal, Vol. 4, No. 1, pp.1-25, https://doi.org/10.1016/S10967494(01)00041-1

Haddow, G., Bullock, J. and Coppola, D.P. (2013) Introduction to Emergency Management, 5th ed., Butterworth-Heinemann, Waltham, MA.

Huxham, C. and Vangen, S. (2000) 'Ambiguity, complexity and dynamics in the membership of collaboration', Human Relations, Vol. 53, No. 6, pp.771-806, https://doi.org/ 10.1177/0018726700536002

Jaeger, P.T., Shneiderman, B., Fleischmann, K.R., Preece, J., Qu, Y. and Fei Wu, P. (2007) 'Community response grids: e-government, social networks, and effective emergency management', Telecommunications Policy, Vol. 31 Nos. 10-11, pp.592-604, https://doi.org/10.1016/j.telpol.2007.07.008

Janowski, T., Pardo, T.A. and Davies, J. (2012) 'Government information networks - mapping electronic governance cases through public administration', Government Information Quarterly, Vol. 29, No. 1, pp.1-10, https://doi.org/10.1016/j.giq.2011.11.003.

Janssen, M. and Estevez, E. (2013) 'Lean government and platform-based governance doing more with less', Government Information Quarterly, Vol. 30, No. 1, pp.1-8, https://doi.org/10.1016/j.giq.2012.11.003

Jansson, U. and Grip, L. (2016) Rätt man på rätt plats! Kommunala sambruksprocesser ur ett genusperspektiv [Right Person in Right Place! Co-operative use of Municipal Resources from a Gender Perspective], Swedish Civil Contingencies Agency (MSB) Report MSB962, Karlstad, ISBN 978-91-7383-635-7.

Johnston, L. and Finegood, D. (2015) 'Cross-sector partnerships and public health: challenges and opportunities for addressing obesity and noncommunicable diseases through engagement with the private sector', Annual Review of Public Health, Vol. 36, No. 1, pp.255-271, https://doi.org/10.1146/annurev-publhealth-031914-122802

Jones, C., Hesterly, W.S. and Borgatti, S.P. (1997) 'A general theory of network governance: exchange conditions and social mechanisms', The Academy of Management Review, Vol. 22, No. 4, pp.911-945, https://doi.org/10.5465/amr.1997.9711022109

Jones, D.M., Lyle, D., Brunero, C., McAllister, L., Webb, T. and Riley, S. (2015) Improving health and education outcomes for children in remote communities: a cross-sector and developmental evaluation approach', Gateways: International Journal of Community Research and Engagement, Vol. 8, No. 1, pp.1-22, ISSN: 1836-3393.

Jungk, R. and Müllert, N.R. (1987) Future Workshops: How to Create Desirable Futures, Institute for Social Inventions, London, UK.

Kleiner, A. and Delurey, M. (Eds.) (2007) The Megacommunity Way: Mastering Dynamic Challenges with Cross-boundary, Leadership, Booz Allen Hamilton. 
Klijn, E. and Koppenjan, J. (2012) 'Governance network theory: past, present and future', Policy and Politics, Vol. 40, No. 4, pp.587-606, 10.7564/14-CGN8.

Klijn, E. and Koppenjan, J. (2014) 'Complexity in governance network theory', Complexity, Governance and Networks, Vol. 1, No. 1, pp.61-70.

Klijn, E., Edelenbos, J. and Steijn, B. (2010) 'Trust in governance networks: its impacts on outcomes', Administration and Society, Vol. 42, No. 2, pp.193-221, https://doi.org/ 10.1177/0095399710362716

Kling, R., McKim, G. and King, A. (2003) 'A bit more to IT: scholarly communication forums as socio-technical interaction networks', Journal of the American Society for Information Science and Technology, Vol. 54, No. 1, pp.47-67.

Leknes, H., Skorge Aartun, E., Christiansen, M. and Andersson Granberg, T. (2017) 'Strategic ambulance location for heterogeneous regions', European Journal of Operational Research, Vol. 260, No. 1, pp.122-133, https://doi.org/10.1016/j.ejor.2016.12.020.

Loukis, E., Janssen, M., Dawes, S. and Zheng, L. (2016) 'Evolving ICT and governance in organisational networks - conceptual and theoretical foundations', Electronic Markets, Vol. 26, No. 1, pp.7-14, https://doi.org/10.1007/s12525-015-0210-1

Melin, U. and Wihlborg, E. (2018) 'Balanced and integrated e-government implementation: exploring the crossroad of public policy-making and information systems project management processes', Transforming Government: People, Process and Policy, Vol. 12, No. 2, pp.191-208, https://doi.org/10.1108/TG-12-2017-0080

Myers, M.D. (2009) Qualitative Research in Business and Management, SAGE Publications Ltd, Los Angeles.

O'Leary, R. and Bingham, L. (2009) The Collaborative Public Manager: New Ideas for the Twenty-first Century, Georgetown University Press, Washington, DC.

Orlikowski, W.J. and Iacono, C.S. (2001) 'Research commentary: desperately seeking the 'IT' in IT research - a call to theorizing the IT artifact', Information System Research, Vol. 12, No. 2, pp.21-134, https://doi.org/10.1287/isre.12.2.121.9700

Palm, J. and Törnqvist, E. (2008) 'Governing the sea rescue service in Sweden: communicating in networks', Journal of Risk Research, Vol. 11, No. 1, pp.269-280, DOI: $10.1080 / 13669870801939449$.

Patton, A. (2007) 'Collaborative emergency management', in Waugh, W.L. and Tierney, K. (Eds.): Emergency Management: Principles and Practice for Local Government, ICMA, Washington, DC, pp.71-85.

Pestoff, V., Brandsen, T. and Verschuere, B. (Eds.) (2013) New Public Governance, the Third sector, and Co-production, Routledge, New York.

Peters, D., Klijn, E-H., Stronks, K. and Harting, J. (2017) 'Policy coordination and integration, trust, management and performance in public health-related policy networks: a survey', International Review of Administrative Sciences, Vol. 83, No. 1, pp.200-222, https://doi.org/10.1177\%2F0020852315585061

Pilemalm S. (2020) 'Volunteer co-production in emergency management in rural areas - using civil citizens and semi-professionals as first responders', e-Journal of e-Democracy (JEDEM), Special Issue, Vol. 12, No. 1, pp.61-86.

Pilemalm, S. (2018) 'Participatory design in emerging civic engagement initiatives in the new public sector: applying PD concepts in resource-scarce organisations', ACM Transactions on Computer-Human Interaction (TOCHI) - Special Issue on Reimagining Participatory Design, Vol. 25, No. 1, Article 5, doi: 10.1145/3152420.

Pilemalm, S., Lindgren, I. and Ramsell, E. (2016) 'Emerging forms of inter-organizational and cross-sector collaborations in e-government initiatives - implications for participative development of information systems', Transforming Government People Process and Policy, Vol. 10, No. 5, pp.603-636. 
Pilemalm, S., Stenberg, R., and Andersson Granberg, T. (2013) 'Emergency response in rural areas', International Journal of Information Systems for Crisis Response and Management, Vol. 5, No. 2, pp.19-31, DOI: 10.4018/jiscrm.2013040102.

Powell, W.W. (1990) 'Neither market nor hierarchy: Network forms of organisation', in Staw, B.M. and Cummings, L.L. (Eds.): Research in Organisational Behavior, JAI Press, Greenwich, CT, pp.295-3369.

Quarantelli, E.L. (2000) Emergencies, Disaster and Catastrophes are Different Phenomena, Disaster Research Center Preliminary Paper, Vol. 304, Disaster Research Centre, University of Delaware.

Ramsell, E., Pilemalm, S. and Andersson Granberg, T. (2017) 'Using volunteers for emergency response in rural areas - network collaboration factors and IT support in the case of enhanced neighbours', ISCRAM 2017: Proceedings of the 14th International Conference on Information Systems for Crisis Response and Management, Albi, Occitanie Pyrénées-Méditerranée, ISCRAM Association, France, pp.985-995.

Schooley, B. and Horan, T. (2007) 'End-to-end enterprise performance management in the public sector through inter-organizational information integration', Government Information Quarterly, Vol. 24, No. 4, pp.755-784.

Schooley, B., Horan, T. and Marich, M. (2010) 'Managing IT collaboration in multiorganizational time-critical services', MISQ Executive, Vol. 9, No. 3, pp.147-161.

Schuler, D. and Namioka, A. (Eds.) (1993) Participatory Design: Principles and Practices, Lawrence Erlbaum Associates, Inc., Hillsdale, NJ.

Simon, A. and Angela, L. (2007) 'The role of nonprofits in disaster response: an expanded model of cross-sector collaboration', Public Administration Review, Vol. 67, No 1, pp.125-142, https://doi.org/10.1111/j.1540-6210.2007.00821.x

Stake, R.E. (2000) 'Case studies', in Denzi, N.K. and Lincoln, Y.S. (Eds.): The SAGE Handbook of Qualitative Research, 2nd ed., SAGE Publications, Inc., Thousand Oaks, pp.119-150.

Turoff, M., Chumer, M., van de Walle, B. and Yao, X. (2004) 'The design of a dynamic emergency response management information system (DERMIS)', Journal of Information Technology Theory and Application (JITTA), Vol. 5, No. 4, Article 3, pp.1-35.

Valenzuela, T.D., Roe, D.J., Nichol, G., Clark, L.L., Spaite, D.W. and Hardman, R.G. (2000) 'Outcomes of rapid defibrillation by security officers after cardiac arrest in casinos', New England Journal of Medicine, Vol. 343, No. 17, pp.206-1209, DOI: 10.1056/ NEJM200010263431701.

Venema, A., Groothoff, J. and Bierens, J. (2010) 'The role of bystanders during rescue and resuscitation of drowning victims', Resuscitation, Vol. 81, No. 4, pp.434-439, https://doi.org/10.1016/j.resuscitation.2010.01.005

Vigoda, E. (2003) Managing Collaboration in Public Administration: the Promise of Alliance among Governance, Citizens, and Businesses, Praege, Westport, CT.

Waugh, W. and Streib, G. (2006) 'Collaboration and leadership for effective emergency management', Public Administration Review, Vol. 66, pp.131-140, https://doi.org/ 10.1111/j.1540-6210.2006.00673.x.

Weber, E.P. and Khademian, A. M. (2008) 'Wicked Problems, knowledge challenges, and collaborative capacity builders in network settings', Public Administration Review, Vol. 68, No. 2, pp.334-349, https://doi.org/10.1111/j.1540-6210.2007.00866.x

Weinholt, A., and Andersson Granberg, T. (2015) 'New collaborations in daily emergency response: applying cost-benefit analysis to new first response initiatives in the Swedish Fire and Rescue Service', International Journal of Emergency Services, Vol. 4, No. 2, pp.177-193, https://doi.org/10.1111/j.1540-6210.2006.00673.x 
Weisfeldt, M.L., Sitlani, C.M., Ornato, J.P., Rea, T., Aufderheide, T.P., Davis, D., Dreyer, J. and Hess, E.P. (2010) 'Survival after application of automatic external defibrillators before arrival of the emergency medical system: Evaluation in the resuscitation outcomes consortium population of 21 million', Journal of the American College of Cardiology, Vol. 55, No. 16, pp.1713-1720, DOI: 10.1016/j.jacc.2009.11.077

Young, D.R. (2000) 'Alternative models of government-nonprofit sector relations: theoretical and international perspectives', Nonprofit and Voluntary Sector Quarterly, Vol. 29, No. 1, pp.149-172, https://doi.org/10.1177\%2F0899764000291009

Yousefi Mojir, K. and Pilemalm, S. (2014) 'Emerging communities of collaboration: co-location in emergency response systems in Sweden', Proceedings of the 2014 Information Systems for Crisis Response and Management Conference (ISCRAM), Pennsylvania State University, USA, pp.548-555.

Yousefi Mojir, K. and Pilemalm, S. (2016) 'Actor-centred emergency response systems: a framework for needs analysis and information systems development', International Journal of Emergency Management, Vol. 12, No. 4, pp.403-420.

Yousefi Mojir, K., Pilemalm, S. and Andersson Granberg, T. (2018) 'Semi-professionals: emergency response as an additional task in current occupations', International Journal of Emergency Services, Vol. 8, No. 2, pp.86-107, doi.org/10.1108/IJES-11-2017-0059

\section{Note}

${ }^{1}$ RAKEL is the Swedish national digital communications system used by the fire services and others in the fields of civil protection, public safety and security, emergency medical services and healthcare (www.msb.se). 